\title{
Pretense Theory and the Imported Background
}

\author{
Jeffrey Goodman \\ Department of Philosophy and Religion, James Madison University, Harrisonburg, USA. \\ Email: goodmajx@jmu.edu \\ Received June 22 ${ }^{\text {nd }}, 2011$; revised July $15^{\text {th }}, 2011$; accepted July 20 ${ }^{\text {th }}, 2011$.
}

\begin{abstract}
Kendall Walton's pretense theory, like its rivals, says that what's true in a fiction F depends in part on the importation of background propositions into F. The aim of this paper is to present, explain, and defend a brief yet straightforward argument—one which exploits the specific mechanism by which the pretense theory says propositions are imported into fictions - for the falsity of the pretense theory.
\end{abstract}

Keywords: Fiction, Truth in Fiction, Pretense, Make-Believe

\section{Introduction}

One of the most influential accounts of truth in fiction is pretense theory, and the foremost proponent of this account is (Walton, 1990) ${ }^{1}$. All of the major theories of truth in fiction $^{2}$-Walton's included - say that it is crucial to understand the mechanism by which propositions which constitute a background for a fiction are imported into the story. That is, all of the major theories say that for every fiction F, there is some set of propositions $\mathrm{S}$ that plays a fundamental role in determining what is true according to $\mathrm{F}$, yet the members of $\mathrm{S}$ are not directly constitutive of $\mathrm{F}$ nor are they entailed ${ }^{3}$ by any proposition (or set of propositions) directly constitutive of $\mathrm{F}$. A proposition $p$ is directly constitutive of a fiction F, let's say, when $p$ is expressed by a token of a sentence in an F story-copy. (For simplicity's sake, I will focus my discussion on literary fictions, but my remarks will apply to non-literary fictions as well.) Background propositions, then, are propositions that may bear on the content of a fiction in an indirect way. On the pretense theory (as well as its rivals), a proposition $p$ in the background set $\mathrm{S}$ may become true in a fiction $\mathrm{F}$ in virtue of $p$ 's being imported into $\mathrm{F}$ by any person or group appropriately related to $\mathrm{F}$. When $p$ is not directly constitutive of $\mathrm{F}$ or entailed by any of the propositions directly constitutive of $F$, but rather when $p$ is true in $\mathrm{F}$ in virtue of being imported into $\mathrm{F}$, let's say that $p$ is indirectly constitutive of $F$.

The aim of this paper is to present, explain, and defend a brief yet straightforward line of reasoning - one which exploits the specific mechanism by which the pretense theory says propositions are imported into fictions-for the falsity of the pretense theory ${ }^{4}$.

\footnotetext{
${ }^{1}$ Other prominent defenders of (some version of) pretense theory include (Byrne, 1993), (Kroon, 2000), (Crimmins, 1998), and (Kim \& Maslen, 2006).

${ }^{2}$ The main rivals being those of (Lewis, 1983) and (Currie, 1990).

${ }^{3}$ When I say “entailed” here, I mean: derivable using either classical or some non-classical (e.g., relevance) logic.

${ }^{4}$ Other philosophers have criticized Walton at length, e.g., (Richard, 2000). But I have seen no one make the very straightforward criticism that I make here. (Walton, 1990) himself addresses the main issue I raise in this paper, but his comments, no matter how they're understood, seem not to constitute an adequate response to my argument against pretense theory (or so I shall argue below).
}

\section{The Argument}

Here is the argument I have in mind:

1) If the pretense theory is correct, then for every literary fiction $F$, what's true in $F$ and what's not true in $F$ will be determined in part by what background propositions are imported into $\mathrm{F}$ by those people appropriately related to $\mathrm{F}$.

2) If what's true in F and what's not true in F is determined in part by what background propositions are imported into $\mathrm{F}$ by those people appropriately related to $\mathrm{F}$, then it's possible that there be some fiction $\mathrm{F}$ such that it's true in $\mathrm{F}$ that $p$ and it's not true in $\mathrm{F}$ that $p$.

3) It is not possible that there be any fiction F such that it's true in $\mathrm{F}$ that $p$ and it's not true in $\mathrm{F}$ that $p$.

4) Therefore, the pretense theory is not correct.

Premise 1 is supported by some pretheoretic intuitions as well as Walton's account of truth in fiction. Pretheoretically, what's true in a fiction $\mathrm{F}$ is not merely a matter of which propositions are directly constitutive of F. For instance, it is true in A Study in Scarlet that Sherlock Holmes' pipe was not manufactured by a wizard, yet the sentence, "Holmes' pipe was not manufactured by a wizard", is neither tokened in any story-copy of A Study in Scarlet nor is it entailed by any of the sentences in any story-copy of A Study in Scarlet. According to the pretense theory (as well as its rivals), the proposition that Holmes' pipe was not manufactured by a wizard is true in A Study in Scarlet because it is a proposition in the background for the story that is imported into the story. What does the pretense theory say must occur for a proposition to become true in a fiction in virtue of being imported into that fiction from the background? And when is it not the case that some proposition is true in a fiction? In order to answer these questions, let us first briefly state some of the fundamental tenets of the pretense theory.

According to Walton, a literary fiction (like all fictions) is a prop in a game of make-believe. (A copy of) A Study in Scarlet, e.g., is a prop that we use to engage our imagination about a fictional detective; we make-believe that Holmes is a flesh and blood, pipe-smoking crime-solver via some novel (just as a child may, via the use of mud, make-believe he is making a genuine chocolate pie). Via certain conditional principles, Walton explains how props generate truths in fiction. That is, for every fiction there are principles that prescribe what is to be 
imagined, hence what is to be true in a fiction, when certain circumstances obtain. The principles that generate fictional truths appeal to the germane conventions (conversational, behavioral, etc.) present in the population of people engaged with the story. So, for example, it may be prescribed that one imagine that there exists a pipe-smoking detective named 'Holmes' whenever one reads a sentence in A Study in Scarlet that apparently quantifies over such a detective (just as it may be prescribed that one imagine that there exists a chocolate pie whenever one sees a round clump of mud).

So, any proposition $p$ that is rightly prescribed to be imagined by the conventions present in the population engaged with a literary fiction F is something that is true in F. Some of these propositions will be directly constitutive of $\mathrm{F}$ (e.g., the ones expressed by sentences originally tokened by Sir Conan Doyle), but not all of them. Some of the propositions that a population is prescribed to make-believe are propositions that are culled from the background. One rightly imagines that London is the most populous city in England when reading A Study in Scarlet even if "London is the most populous city in England" is nowhere tokened in any story-copy. In virtue of its being imported in this way into the story, this proposition is just as true in the fiction as any proposition that is directly constitutive of the story.

Of course, not all propositions in the background of a story ought to be imagined by those engaged with the story. The propositions that are not prescribed to be imagined are those that the conventions in place make irrelevant to the subject matter of the story; if there is no convention that generates the appropriate imaginative acts in the population engaged with the story regarding some background proposition $p$, then $p$ is not true in the story. For example, one ought not imagine that Holmes' pipe was manufactured by a wizard when reading $A$ Study in Scarlet. The relevant proposition is utterly irrelevant to the subject matter of the story. Thus, the proposition is rightly not imported into the story, is thus not indirectly constitutive of the fiction, and is thus not true in A Study in Scarlet ${ }^{5}$.

So, it is via the appropriate conventions present in a population that propositions in the background for a fiction $\mathrm{F}$ become true in F. We should also note that the members of the background that are eligible for importation need not be true propositions; some false propositions may rightly be imported into some stories ${ }^{6}$. What's central to the pretense account is simply

${ }^{5}$ The issues surrounding which propositions are relevant or irrelevant to a story and the mechanisms by which a proposition gets rightly imported or rightly fails to get imported are ones that are incredibly complex. At the very least, Gricean conversational maxims and other subtle conventions of communication and behavior must be appealed to in order to do these issues justice. However, I do not think these matters are hopelessly complex, and they are ones that, in principle, could be dealt with coherently and completely. For my purposes here, however, all we will need is an example whereby-no matter what the specifics are surrounding the germane conventions in the relevant populations-Walton's theory entails that some particular proposition both should and should not be imported into some story.

${ }^{6}$ Philosophers often speak of background facts that get imported into stories. However, as (Lewis, 1983: p. 274) points out, the proposition that there exists an animal that breathes fire, e.g., may rightly be imported into a typical story about dragons. Lewis would call this a case of "inter-fictional carry-over" of a proposition into a story rather than a case of importation of a proposition from the background. However, the false proposition that something breathes fire, I assert, may be true in a fiction F even when that proposition is not imported from any other fiction $\mathrm{G}$ (or even any genre of fiction). A population may (wrongly) believe in fire-breathing animals for scientific reasons. What seems to matter is merely whether or not the proposition in question is relevant in the right sort of way to the subject matter of $F$. whether the person engaged with the fiction is indeed prescribed to imagine $p$ by the appropriate conventions of the game of which that fiction is a prop. A person may be engaged with a fiction $F$ and mistakenly think that $p$ ought to be imported, but let us say that when $p$ is rightly imported by someone into $\mathrm{F}$ given the germane conventions in place, that person is competently engaged with $F$.

Premise 2 is obviously the crux of the above argument, and its force can now be made clear. It's possible that there be distinct people, each of whom are competent readers of some fiction $\mathrm{F}$, yet some proposition $p$ is prescribed by $\mathrm{F}$ given the relevant conventions in the population to which the first person belongs, while it is simultaneously not the case that $p$ is prescribed by $\mathrm{F}$ given the relevant conventions in the population to which the second person belongs. On Walton's account, it thus follows that $p$ will be both true in $\mathrm{F}$ and it will not be the case that $p$ is true in $\mathrm{F}^{7}$. (I of course will not be arguing for the claim here that there are no fictions in which $p$ is both true and not true; of course there are "fictional worlds" that internally involve contradiction in this way. But if there is any case in which 'in fiction $\mathrm{F}, p$ ' is true yet it's also not the case that "in $\mathrm{F}$, $p$ " is true, then we are left with a "real world" contradiction. And dialetheist ${ }^{8}$ views notwithstanding, this seems to me be to be an intolerable breach of logic.)

Consider the following short work of fiction. Call it Earth Story.

"Once upon a time on planet Earth, the very planet we live on, there were intelligent non-human creatures that walked, talked and behaved very much like we behave. The end”.

Suppose Alex is part of a population of people here on Earth and Alex engages himself with Earth Story. And suppose further that everyone in Alex's population has reason to believe that Earth is the shape of a flat disc roughly 10,000 miles in diameter resting on the back of a turtle. The above copy of Earth Story never includes any sentence tokens about the shape of the Earth, nor do any of its sentence tokens entail anything about its shape. Part of what's true in Earth Story, though, by virtue of what's directly constitutive, is the proposition that intelligent non-humans once lived on Earth. Given the relevant conventions present in Alex's population, Alex is competently engaged with Earth Story; he thus rightly imports into the story the background proposition that intelligent non-humans once lived on a disc that is roughly 10,000 miles in diameter resting on the back of a turtle. So, the proposition that intelligent nonhumans once walked on a disc that rests on the back of a turtle, e.g., will be true in Earth Story.

Now consider Boris. He engages himself with Earth Story as well, yet Boris is part of a population who (reasonably) all believe that Earth is an oblate spheroid. Given the relevant conventions present in Boris's population, Boris is competently engaged with Earth Story; he thus rightly imports into the story the background proposition that intelligent non-humans once lived on an oblate spheroid. Further, it will not be prescribed by any convention in Boris's population that Boris imagine that intelligent non-humans once lived on a flat and finite disc roughly 10,000 miles in diameter resting on the back of a turtle. So, the proposition that intelligent non-humans once walked on

${ }^{7}$ (Lewis, 1983: p. 272) addresses this sort of problem for his own view, but manages to cut off this worry by rigidly tying what's imported into a story to the prevailing beliefs of the community in which the story originated.

${ }^{8}$ See, e.g., (Priest, 1987). 
a disc that rests on the back of a turtle, e.g., will not be true in Earth Story.

\section{Objections and Replies}

By my lights, there are only two sorts of replies that can be made to premise 2. Let us call the first the non-competency reply. On this reply, premise 2 is false because it's not true that the relevant proposition is both true in Earth Story and not true in Earth Story. It must be the case that either Alex or Boris fails to be competently engaged with the fiction.

I can't see any way to make this reply plausible. No matter what the relevant (conversational, behavioral, etc.) conventions are in the populations of Alex and Boris which govern what they ought to imagine, I can see no reason to suppose that either must be violating any of those conventions when they engage with Earth Story.

The second sort of reply to premise 2 we may call the context-dependency reply. Walton goes to great lengths to explain this line of response; ${ }^{9}$ his reasoning has been summarized by (Kim and Maslen, 2006):

Sometimes there are two (or more) incompatible yet perfectly reasonable readings of a novel. Applying Walton's term "authorized game" to these cases, there are two kinds of games authorized by the story, and in each kind of game, different background facts are imported.

... [T] he facts that are imported into a story are generated in a similar way to the way that facts that are merely implied in a conversation are generated. Sometimes the context in which a conversation occurs determines one reading over another... In a similar way, different contexts in which a story occurs may determine different readings of the story by determining which background facts are legitimately imported or brought into the story in that context ${ }^{10}$.

A nice example is Henry James's The Turn of the Screw. Some literary critics argue that the ghosts in the story are real, and others that the ghosts are the governess's hallucinations. These two incompatible readings may well both be reasonable $^{11}$.

I have a hard time figuring out the most charitable way to understand this reply. However, no matter what Walton means by "authorized games", and no matter how different contexts generate different conventions governing what we ought to imagine, it seems to me that there are only three possible ways to construe this response to premise $2^{12}$.

First interpretation of context-dependency reply: whenever contexts of interpretation differ in the way that I described above regarding Alex and Boris, it turns out that one is dealing with two distinct stories. Premise 2 is not supported by the example above because in such a hypothetical case you wind up with one story that Alex is competently engaged with and a distinct story that Boris is engaged with. We may have just one name for both stories, and the stories may have much in com-

\footnotetext{
${ }^{9}$ See (Walton, 1990: pp. 285-287).

${ }^{10}$ (Kim \& Maslen, 2006: p. 90).

${ }^{11}$ (Kim \& Maslen, 2006: p. f22).

${ }^{12}$ Let us note first, though, that however this reply is to be construed, it simply cannot amount to the claim that "in fiction F, $p$ " and "not: in fiction F, $p$ " are both true whenever either the right understanding of proposition $p$ or the whole fiction $\mathrm{F}$ is context dependent. No matter how context dependency is construed that would still amount to the endorsement of a true contradiction.
}

mon, but it's just not the case that it is both true and not true according to some unique story that intelligent non-humans once walked on a disc that rests on the back of a turtle. Whenever different conventions are in place that prescribes different imaginings to different people engaged with a fiction, this is enough to make for a difference in the stories that each engages.

This interpretation of the context-dependency reply seems to accord well with the idea that fictions are socially defined entities. But this reply does violence to the idea that there can be two incompatible yet reasonable interpretations of one and the same fiction. It seems perfectly reasonable to say that both Alex and Boris are engaged with a unique fiction, viz., Earth Story, and they are in disagreement about what is true in it.

Second interpretation of the context-dependency reply: whenever contexts of interpretation differ in the way that I described above regarding Alex and Boris, it turns out that each must be dealing with two distinct background propositions. Premise 2 is not supported by the example above because in such a hypothetical case you wind up with one proposition that Alex rightly imports into Earth Story in virtue of the prevailing flat-earthbelief circumstances he is in, and a distinct proposition that Boris rightly fails to import into Earth Story in virtue of the prevailing spheroid-earth-belief circumstances he is in. So, it's just not the case that it is both true and not true according to some unique story that intelligent non-humans once walked on a disc that rests on the back of a turtle; it's true according to Earth Story that intelligent-non-humans-once-walked-on-a-disc-that-rests-onthe-back-of-a-turtle-in-Alex's-context but it's not the case that this very proposition is also not true in the story.

This version of the context-dependency reply seems to be the one that is best supported by the Kim and Maslen summary from above. However, this version of the reply seems to me to fare no better than the first. If this reply were correct, then it would turn out that two reasonable people-whenever they disagree about the correct interpretation of a work of fiction in virtue of being in different circumstances where different conventions are generated-can never be disagreeing about whether or not one and the same proposition is true in some fiction F. Suppose Alex and Boris meet. The question is posed to them: "Is it true in Earth Story that intelligent non-humans once walked on a flat disc with a 10,000 mile circumference resting on the back of a turtle?” One will say yes, one will say no. This seems to me to be reflective of a genuine disagreement about the inclusion or non-inclusion of a unique proposition in Earth Story by two people competently engaged with the fiction.

Third interpretation of the context-dependency reply: whenever contexts of interpretation differ in the way that I described above regarding Alex and Boris, it turns out that the unique fiction each is competently engaged with is one that makes two incompatible background propositions true. Premise 2 is not supported by the example above because in such a hypothetical case you wind up with a story in which it is true that intelligent non-humans once walked on a flat disc with... and it is also true in the story that no intelligent non-humans ever walked on a flat disc with... Whenever two people disagree based on context in the way the example relies on, each is competently engaged with an impossible fiction; Alex rightly imports one proposition $p$ into Earth Story while Boris rightly imports not-p into Earth Story. 
This version of the reply does, of course, allow the pretense theorist to avoid the contradiction. Negation does not always push through "according to" or "it is true in the story" operators, so if it is true in Earth Story that no intelligent non-humans ever walked on a flat disc..., that does not entail that it is not true in Earth Story that intelligent non-humans once walked on a flat disc... However, this version of the context-dependency reply just does not present a plausible account of what's going on in the case of Alex and Boris. There are many impossible fictions to be sure, but Earth Story is just not one of them. Alex and Boris are in disagreement in a very straightforward sort of way regarding the shape of a thing that, according to the story, was once walked on by some intelligent non-humans; neither would assent to the idea that the story says that such creatures both did and did not walk on a flat disc...

\section{Conclusion}

My aims here were not to introduce any novel account of truth in fiction or argue for any alternative to pretense theory. My goal was a more modest one; I simply wished to maintain that that while Earth Story is a unique fiction, the lesson to be learned from it is perfectly general. The example demonstrates that the pretense account of truth in fiction cannot be correct.

\section{References}

Byrne, A. (1993). Truth in fiction: The story continued. Australasian Journal of Philosophy, 71, 24-35. doi:10.1080/00048409312345022

Crimmins, M. (1998). Hesperus and phosphorous: Sense, pre-tense, and reference. The Philosophical Review, 107, 1-48. doi:10.2307/2998314

Currie, G. (1990). The nature of fiction. Cambridge, MA: Cambridge University Press.

Kim, S., \& Maslen, C. (2006). Counterfactuals as short stories. Philosophical Studies, 129, 81-117. doi:10.1007/s11098-005-3022-x

Kroon, F. (2000). Negative existentials. In A. Everett, \& T. Hofweber (Eds.), Empty names, fiction and the puzzles of non-existence (pp. 95-116). Stanford, CA: Center for the Study of Language and Information Publications.

Lewis, D. (1983). Truth in fiction. Philosophical papers, 1 (pp. 261275). New York, NY: Oxford University Press. doi:10.1093/0195032047.003.0015

Priest, G. (1987). In contradiction. Dordrecht: Martinus Nijhoff. (2nd expanded ed.). Oxford: Oxford University Press, 2006.

Richard, M. (2000). Semantic pretense. In A. Everett, \& T. Hofweber (Eds.), Empty Names, fiction and the puzzles of non-existence (pp. 205-232). Stanford, CA: CSLI Publications.

Walton, K. (1990). Mimesis as make-believe. Cambridge, MA: Harvard University Press. 